\title{
Relative Contribution of Social Factors to University Students' Compliance with Traffic Rules: The Case of Al-Ahsa Province, Saudi Arabia
}

\author{
Ahmed R. Elsayed \\ Professor of Special Education, \\ Faculty of Education, \\ King Faisal University, Saudi Arabia \\ Abdullah M. Alharbi \\ Professor of Foundations of Education, \\ Faculty of Education, \\ University of Hafr Al Batin, \\ Hafar Al Batin 39524, Saudi Arabia \\ Gamal A. Adam \\ Assistant Professor of Anthropology, \\ Department of Social Work, \\ Faculty of Arts, University of Hafr Al Batin, \\ Hafar Al Batin 39524, Saudi Arabia \\ Corresponding Author
}

DOI: https://doi.org/10.36941/jesr-2021-0091

\section{Abstract}

This study aimed to reveal the relative contribution of social factors to compliance of university students with traffic rules at King Faisal University for Males in Al-Ahsa governorate, Saudi Arabia, and to reveal the differences in compliance with traffic rules between students of sciences and humanities. The sample of the study consisted of 874 students and it was conducted during the second semester of the academic year 2017-18. The participants were 381 from sciences and 493 from humanities. The authors used social factors and compliance with traffic rules as measurement tools and found out that three models of factors, including family, education and community to be statistically significant to the compliance of university students who drive with traffic rules. The results further showed that there are statistically significant differences in average scoring between students of sciences and students of humanities regarding the social factors that make them comply with traffic rules with science students complying more with traffic rules than their counterparts in humanities.

Keywords: social factors, compliance with traffic rules, university students

\section{Introduction}

Youth in general and university students in particular are a principal potential power for the future of human societies and therefore their preparation for the leadership of their societies in all domains is 
critical. Their training must happen in such a way that would help them embrace innovation without rejection to conventional cultural values and traditions. However, as young people are full of energy, there is a possibility that that energy will lead them to harmful activities if it is not invested in productive fields (Hamad, 2008). Therefore, it is important that societies galvanize the energy of their youth toward the development of communities. A main harmful activity in which many young people are involved in these days is reckless driving that results in accidents and causes consequently human and material losses (Lee \& Al-Mansour, 2019; Ludovic, Ordonneau, Plot, Toillon, Ingrand \& Romo, 2017; Weichbrodt, 2015). Some observations conclude that more than a million individuals die every year in traffic accidents (Castillo-Manzano, Castro-Nuno, Lopez-Valpuesta \& Pedrega, 2019). Although the location, the road, environmental conditions and condition of vehicle can cause traffic accidents, the focus of this study is on social factors, which contribute to the respect or violations of traffic rules, including family, school and community. Most particularly, this study aims to explore the extent to which social factors, such as family, school, and community contribute to the reduction of accident rates among students of King Faisal University for Males in Al-Ahsa Province in Saudi Arabia.

Compliance with traffic rules is more than individual drivers' responsibility, it is a social responsibility to which intuitions such as family, school, and media must contribute to enlighten young people about the importance of compliance with traffic rules and safe driving (Zhang, Tan, \& Jou, 2016). These, and many other institutions, must teach people about the importance of compliance with traffic rules. Education of people about traffic rules and driving standards since when they are children is crucial, because the rules will be rooted as a principal part of the culture of society and people will not be allowed to drive until they reach an age that qualifies them to drive after satisfactory training and certification from relevant traffic authorities (Al-Radadi, 2013; Fadhil, 2013).

The authors observed that there has recently been a rapid increase in traffic accidents in Saudi Arabia and discovered in the literature that the increase in accidents rates in Saudi Arabia coincides with huge evidence of increase in accidents rates in different parts of the world, which spurred them to conduct the present study (Garrido, Rodríguez, Castro, Fernández, \& Soriano, 2018; Ladi, 2014, 2016; Yusuf, 2017; Zhang, Ge, Qu, Zhang \& Sun, 2018). The literature shows that traffic accidents are main factors of social, economic and psychological problems that many people in various societies experience, and that, in most cases, young drivers are both reasons and victims of traffic accidents. For example, the World Health Organization (2015) reports that traffic accidents claim 1.5 million lives worldwide every year and that the majority of victims are individuals aged between 15 and 29 years. Moreover, some studies uncover that 4.7 percent of the total number of deaths worldwide are caused by traffic accidents (Lee and Al-Mansour, 2019). Lee and Al-Manour (2019) further document that traffic accidents resulted in 7489 deaths and 33139 injuries in Saudi Arabia in 2017. Other studies list factors, including personal and family factors, educational factors, social factors, and institutional factors as chief behind drivers' non-compliance with traffic rules and involvement in accidents (Holman \& Popusoi, 2018; Mawanga \& Ntayi, 2010; Trueloves, Freeman \& Davey, 2019; Xu, Li \& Jiang, 2014).

The main question the current study is trying to answer is, to what extent do social factors contribute to compliance of university students with traffic rules in Al-Ahsa Province, in Saud Arabia? From this main question the following sub-questions have branched out. The first question is, what are the social factors that can help university students who drive to comply with traffic rules? The second question is, to what extent differences in grade averages between students of sciences and students of humanities are measurable to levels of social factors related to traffic accidents? And to what extent differences in students' grade averages are measurable to their compliance with traffic rules?

A theoretical significance of the study lies in the recent increases of traffic accidents resulting in deaths, injuries and disabilities, which seriously affect families, communities and the wider society. The majority of accidents are usually caused by reckless driving and other types of behavior that violate traffic rules. Another theoretical significance of the study lies on the sample used-university students in $\mathrm{Al}$ Ahsa Province, because students are the majority in university communities and those who drive 
among them are young drivers, and young drivers' contribution to accidents is higher compared to that of older drivers (Abdul Majid, Al-Daghheri, \& Faraj, 2014; Najmi, 2017). Therefore, the authors found that it is crucial to investigate if social factors (i.e. familial, educational, and communal factors) can possibly contribute to young drivers' awareness of safe driving and avoidance of traffic accidents, or if some of these factors could be reasons for driver's involvement in traffic accidents.

The empirical significance of the study is that it designs measurements that link university students' compliance with traffic rules to social factors (e.g. family, school, and community factors). It measures social factors against traffic accidents. The study also is a pioneer in making recommendations about training young men in general and university students in particular on traffic rules, and further encourages community institutions in general and educational institutions in particular to contribute to the enlightenment of university students who drive in observing traffic rules because that would contribute to safe and happy living conditions.

\section{Methodology}

The study uses a descriptive methodology to explore contribution of social factors to university students' compliance with traffic rules in Al Ahsa Province and to delineate differences in levels of compliance between students of sciences and humanities. The study location is King Faisal University for Males which consisted of 10768 students of sciences and humanities during the second semester of the academic year 2017-2018 when the study was carried out. The total number of students in science sections was 4749 students and that of students of humanities was 6019 students. A random sample of 874 students was drawn, including 381 students of sciences and 493 students of humanities, and a questionnaire was distributed to them.

\subsection{Measurement of Social Factors}

The questionnaire that was distributed consisted of two scales: one for social factors and another for compliance with traffic rules. The scale for social factors consisted of three dimensions, including family dimension, school dimension and community dimension; and a pattern of Likert scale of "always", "sometimes" and "scarcely" was utilized to explore them. The authors assigned 3 marks for "always", 2 for "sometimes" and 1 for "scarcely". The final draft of the scale consisted of 27 sections each of which consisted of three main dimensions, with the first dimension consisting of eight sections, the second ten, and the third nine sections.

The first draft of the questionnaire was tested on 126 students to make sure about its validity and reliability. Three different ways were used in testing the reliability of the scale, including validity of arbitrators, internal consistency and terminal comparison validity. Regarding the validity of arbitrators, the authors presented the draft of the questionnaire to ten professors from different disciplinary backgrounds, including education, psychology, mental health and sociology at King Faisal University to make sure about the reliability of the scale. They were asked to provide their opinion about the sections of the questionnaire and about the extent to which its scale corresponded to the purpose of the study. The sections of the first draft of the questionnaire were 30 sections and each of them consisted of ten dimensions at the time when the questionnaire was presented to the arbitrators and then its final draft was reduced to 27 sections based on the arbiters' comments. Regarding internal consistency, the authors extracted the coefficients of internal consistency of the scale of social factors calculating double correlation coefficient between the score of each section in a dimension alone and the total score of the dimension, on the one hand, and between the score of each dimension and total score of the scale of social factors as explained in Table 1 , on the other hand. 
Table 1: Internal consistency of sections and dimensions of social factors scale $(\mathrm{N}=126)$

\begin{tabular}{|c|c|c|c|c|c|}
\hline $\begin{array}{c}\text { Family } \\
\text { dimension }\end{array}$ & $\begin{array}{c}\text { Consistency } \\
\text { of coefficients }\end{array}$ & $\begin{array}{c}\text { School } \\
\text { dimension }\end{array}$ & $\begin{array}{c}\text { Consistency } \\
\text { of coefficients }\end{array}$ & $\begin{array}{c}\text { Community } \\
\text { dimension }\end{array}$ & $\begin{array}{c}\text { Consistency } \\
\text { of coefficients }\end{array}$ \\
\hline 1 & 0.056 & 3 & $0.593^{* *}$ & 5 & $0.419^{* *}$ \\
\hline 2 & $0.534^{* *}$ & 4 & $0.570^{* *}$ & 6 & 0.157 \\
\hline 7 & $0.395^{* *}$ & 9 & $0.531^{* *}$ & 11 & $0.411^{* *}$ \\
\hline 8 & $0.486^{* *}$ & 10 & $0.547^{* *}$ & 12 & $0.525^{* *}$ \\
\hline 13 & $0.294^{* *}$ & 15 & $0.422^{* *}$ & 17 & $0.522^{* *}$ \\
\hline 14 & 0.057 & 16 & $0.489^{* *}$ & 18 & $0.430^{* *}$ \\
\hline 19 & $0.377^{* *}$ & 21 & $0.256^{* *}$ & 23 & $0.472^{* *}$ \\
\hline 20 & $0.358^{* *}$ & 22 & $0.517^{* *}$ & 24 & $0.451^{* *}$ \\
\hline 25 & $0.462^{* *}$ & 27 & $0.594^{* *}$ & 29 & $0.530^{* *}$ \\
\hline 26 & $0.443^{* *}$ & 28 & $0.446^{* *}$ & 30 & $0.317^{* *}$ \\
\hline $\begin{array}{l}\text { dimension is } \\
\text { linked to scale }\end{array}$ & $0.372^{* *}$ & $\begin{array}{l}\text { dimension is } \\
\text { linked to scale }\end{array}$ & $0.387^{* *}$ & $\begin{array}{l}\text { dimension linked } \\
\text { to the scale }\end{array}$ & $0.604^{* *}$ \\
\hline
\end{tabular}

** Function at level (o.01) * Function at level (0.05)

Table 1 illustrates that most of the coefficients associated with each section and the dimension to which they belong are functioning statistically at 0.01, whereas others are functioning at 0.05 . Table 1 also shows that sections 1 and 14 in the family dimension and section 6 in the community dimension are not statistically significant and are therefore excluded from the scale. The table further explains that all coefficients of the correlation of dimensions of social factors scale in the overall degree of the scale are statistically functional at $\mathbf{0 . 0 1}$, which has made the authors trust the reliability of the sections of the scale and its main dimensions, and therefore the number of sections of the scale in its final form have become 27 paragraphs divided into three dimensions so that the first dimension contained eight sections, the second ten sections, and the third nine sections.

The authors calculated the validity of the peripheral comparison by comparing the highest and lowest quadrants of respondents' grades' averages on the scale of social factors, and then calculated the value of (t-test) in the average of each quadrant in order to calculate the differential strength of the scale. The results show that the value of (t-test) of the first, second, third dimensions and total score of the scale are 3.88, 3.75, 4.41, and 4.02 respectively; and all of them are functional statistically at 0.01 , which means that significant differences exist between the averages of the highest and the lowest quadrants of dimensions of the scale of social factors and the differences are statistically functional at o.o1. This indicates that the scale differentiates between higher and lower responses significantly, which further confirms its validity and reliability. Regarding the reliability of the scale of social factors, the researchers have utilized Spearman-Brown's method of split-half reliability and Cronbach's Alpha to probe it as illustrated in Table 2.

Table 2: Reliability of dimension of social factors' scale based on Spearman-Brown Split-Half Reliability and Cronbach's Alpha

\begin{tabular}{|l|c|c|c|}
\hline Dimensions & $\begin{array}{c}\text { Number of } \\
\text { paragraphs }\end{array}$ & $\begin{array}{c}\text { Stability factor } \\
\text { (Spearman-Brown) }\end{array}$ & $\begin{array}{c}\text { Stability factor } \\
\text { (Cronbach's Alpha) }\end{array}$ \\
\hline Family. & 10 & 0.794 & 0.795 \\
\hline School. & 10 & 0.728 & 0.816 \\
\hline Community & 10 & 0.777 & 0.754 \\
\hline Overall grade of the scale. & 30 & 0.770 & 0.845 \\
\hline
\end{tabular}


Table 2 shows that all coefficients of the dimensions of social factors' scale and the total score of the scale are highly reliable and consistent when they are tested according to Spearman-Brown's split-half reliability and Cronbach's Alpha. The reliability of coefficients ranges from 0.728 to 0.777 in SpearmanBrown split-half measurement and from 0.754 to 0.845 in Cronbach's Alpha, which convinced the authors that the scale is reliable.

\subsection{Measurement of Compliance with Traffic Rules}

The measurement of compliance with traffic rules consisted of 25 sections and it aimed to measure the degree of student drivers' compliance with traffic rules, using Likert triplet scale of "always", "sometimes", and "rarely" answers with always equaling 3 marks, sometimes 2 , and rarely 1 marks. The final draft of the questionnaire was reduced to 23 sections after revisions and testing. The same steps were followed to test consistency, reliability and validity of social factors scale, and to measure the scale of compliance with traffic rules, which means that it was tested on the same sample of 126 students in order to make sure that the scale is consistent.

The questionnaire was presented the same group of ten professors from education, psychology, mental health and sociology to review it and make sure that it was reliable before it was considered as the final draft. The arbitrators were asked about the clarity of all sections of the scale that were initially 25 sections. One section was removed because it scored lower than $80 \%$ of reviewers' approval and other sections were modified based on the reviewers' comments to combine some sections together and the number of sections was finally reduced to 23 sections.

Regarding the internal consistency, the authors extracted the internal consistency of coefficients of traffic compliance in the scale by calculating the correlation coefficients between the degree of each section of the scale and its overall score as illustrated in Table 3.

Tablez: Internal consistency of sections of traffic compliance scale

\begin{tabular}{|c|c|c|c|c|c|c|c|}
\hline \begin{tabular}{|l|} 
Paragraph \\
\end{tabular} & \begin{tabular}{|c|} 
Consistency \\
of coefficients
\end{tabular} & Paragraph & \begin{tabular}{|c|} 
Consistency \\
of coefficients
\end{tabular} & Paragraph & \begin{tabular}{|c|}
$\begin{array}{c}\text { Consistency } \\
\text { of coefficient }\end{array}$ \\
\end{tabular} & Paragraph & $\begin{array}{l}\text { Consistency } \\
\text { of coefficient }\end{array}$ \\
\hline 1 & $0.256^{* *}$ & 7 & $0.307^{* *}$ & 13 & $0.225^{* *}$ & 19 & $0.324^{* *}$ \\
\hline 2 & 0.138 & 8 & $0.184^{*}$ & 14 & $0.417^{* *}$ & 20 & $0.251^{* *}$ \\
\hline 3 & $0.178^{*}$ & 9 & $0.279^{* *}$ & 15 & $0.419^{* *}$ & 21 & $0.333^{*}$ \\
\hline 4 & $0.353^{* *}$ & 10 & $0.394^{* *}$ & 16 & $0.425^{* *}$ & 22 & $0.349^{* *}$ \\
\hline 5 & $0.208^{*}$ & 11 & $0.251^{* *}$ & 17 & $0.211^{*}$ & 23 & $0.397^{* *}$ \\
\hline 6 & $0.177^{*}$ & 12 & $0.366^{* *}$ & 18 & $0.203^{*}$ & 24 & $0.336^{* *}$ \\
\hline
\end{tabular}

** Function at level (o.01) * Function at level (0.05)

Table 3 explains that most of the correlation coefficients of each section and their association to the total score of the scale are statistically functional either at o.o1or at 0.05 , except section two which's correlation coefficients were not statistically functional and was therefore eliminated to settle the number of the sections of the scale of traffic compliance at 23 sections. To make sure about the validity of peripheral comparison, the researchers compared highest and lowest quadrants of students' marks on the compliance with traffic rules scale and then calculated the value of (t-test) of the average of each quadrant according to differential strength of the scale, which has resulted in value of (t-test) being 3.11 and it means that the differences between averages of quadrants are statistically functional at 0.01 on the scale of traffic compliance. This indicates that the scale is valid in calculating higher and lower responses.

Spearman-Brown's split-half measurement and Cronbach's Alpha test are used to probe the validity of the scale of compliance with traffic rules and the validity of coefficients were 0.796 and 0.793 respectively which confirms the constancy of the scale. 


\section{Results}

\subsection{Verification of Results of the First Hypothesis}

The assumption of this hypothesis is that social factors contribute significantly to university student drivers' compliance with traffic rules, which is statistically functional. The authors utilized progressive multiple regression analysis to verify the extent to which social factors contribute to the prediction of student drivers' compliance with traffic rules as following tables illustrate.

Table 4: Results of progressive multiple regression analysis and values of $(\mathrm{P})$ for social factors as independent variables and prediction of university students' compliance with traffic rules as a dependent variable $(\mathrm{n}=874)$

\begin{tabular}{|c|c|c|c|c|c|}
\hline Form & $\begin{array}{c}\text { Total } \\
\text { squares }\end{array}$ & $\begin{array}{c}\text { Degrees of } \\
\text { freedom }\end{array}$ & $\begin{array}{l}\text { Average } \\
\text { squares }\end{array}$ & $\begin{array}{l}\text { Value } \\
\text { of (P) }\end{array}$ & $\begin{array}{c}\text { Level of } \\
\text { significance }\end{array}$ \\
\hline \multirow{3}{*}{ (I) Family factors } & 728.669 & 1 & 728.669 & \multirow{3}{*}{21.404} & \multirow{3}{*}{0.000} \\
\hline & 29685.725 & 872 & 34.043 & & \\
\hline & 30414.394 & 873 & & & \\
\hline \multirow{3}{*}{ (II) Family and School } & 2905.828 & 2 & 1452.914 & \multirow{3}{*}{46.003} & \multirow{3}{*}{0.000} \\
\hline & 27508.566 & 871 & 31.583 & & \\
\hline & 30414.394 & 873 & & & \\
\hline \multirow{3}{*}{ (III) Family, school, and community } & 3351.028 & 3 & 1117.009 & \multirow{3}{*}{$35 \cdot 908$} & \multirow{3}{*}{0.000} \\
\hline & 27063.365 & 870 & 31.107 & & \\
\hline & 30414.394 & 873 & & & \\
\hline
\end{tabular}

Table 4 shows that the value of $(\mathrm{P})$ for both the first, second and third models is statistically significant at 0.01 .

Table 5: Coefficient values of final models for progressive multiple regression analysis of social factors and predicted compliance with traffic rules among study sample members $(n=874)$

\begin{tabular}{|c|c|c|c|c|c|c|c|}
\hline Form & \begin{tabular}{|l}
$\begin{array}{l}\text { Independent } \\
\text { variables }\end{array}$ \\
\end{tabular} & $\begin{array}{c}\text { Confidents of } \\
\text { Regression value of }(\mathrm{B}) \\
\end{array}$ & $\mathbf{R}$ & ${ }^{2} \mathbf{R}$ & $\begin{array}{c}{ }^{2} \mathbf{R} \\
\text { Corrector } \\
\end{array}$ & $\mathrm{T}$ & \begin{tabular}{|c|} 
Level of \\
significance
\end{tabular} \\
\hline \multirow{2}{*}{$\begin{array}{l}\text { (I) } \\
\text { Family }\end{array}$} & \begin{tabular}{|l} 
Steady \\
regression
\end{tabular} & 51.094 & \multirow{2}{*}{0.155} & \multirow{2}{*}{0.024} & \multirow[t]{2}{*}{0.0 .23} & 35.666 & 0.000 \\
\hline & Family & 0.315 & & & & 4.626 & 0.000 \\
\hline \multirow{3}{*}{$\begin{array}{l}\text { (II) } \\
\text { Family and school }\end{array}$} & $\begin{array}{l}\text { Steady } \\
\text { regression }\end{array}$ & 44.693 & \multirow{3}{*}{0.309} & \multirow{3}{*}{0.096} & \multirow{3}{*}{0.093} & 28.276 & 0.000 \\
\hline & \begin{tabular}{|l|} 
Family \\
\end{tabular} & 0.255 & & & & 3.862 & 0.000 \\
\hline & School & 0.361 & & & & 8.303 & 0.000 \\
\hline \multirow{4}{*}{$\begin{array}{l}\text { (III) } \\
\text { Family, school and } \\
\text { community }\end{array}$} & $\begin{array}{l}\text { Steady } \\
\text { regression }\end{array}$ & 42.931 & \multirow{4}{*}{0.332} & \multirow{4}{*}{0.110} & \multirow{4}{*}{0.107} & 26.236 & 0.000 \\
\hline & \begin{tabular}{|l|} 
Family \\
\end{tabular} & 0.154 & & & & $2.18 \mathrm{o}$ & 0.03 \\
\hline & School & 0.288 & & & & 6.099 & 0.000 \\
\hline & Community & 0.254 & & & & 3.783 & 0.000 \\
\hline
\end{tabular}

Tables 4 and 5 show that the regression of coefficients for the three models in the regression of equations are statistically significant at 0.01 , except the family dimension in the third model that was statistically functional at 0.05 , which indicates that family, study and community factors are 
statistically functional and contribute significantly to the prediction of young university motorists' compliance with the traffic rules, which can be predicted by the following multiple gradient equations.

Model 1: Compliance with traffic rules = steady regression + (coefficients of regression of family factors $\times$ score of family factors).

Compliance with traffic rules $=51.094+(0.315 \times$ score of family factors $)$.

Model II: Compliance with traffic rules = steady regression+ (regression of coefficients of family factors $\times$ score of family factors) + (regression of coefficients of study factors $\times$ score of study factors) . factors).

Compliance with traffic rules $=44.693+(0.255 \times$ family factors score $)+(0.361 \times$ score of study

Model 3: Compliance with traffic rules = steady regression+ (regression of coefficients of family factors $\times$ score of family factors) + (coefficients of regression of study factors $\times$ score of study factors) + (coefficients of regression of societal factors $\times$ score of societal factors).

Compliance with traffic rules $=42.931+(0.154 \times$ score of family factors $)+(0.288 \times$ score of study factors $)+(0.254 \times$ score of community factors $)$.

\subsection{Results of verification of the second hypothesis}

This hypothesis states that there are no statistically significant differences between the average marks of science and humanity students on the scale of social factors. The researchers used (t-test) for independent groups to investigate if the averages of grade differences between science and humanity students are statistically functional on the scale of social factors as shown in Table 6.

Table 6: The differences between the average grades of students of sciences and humanities on the scale of social factors

\begin{tabular}{|c|c|c|c|c|c|c|c|}
\hline Dimension & Specialization & Number & \begin{tabular}{|c|} 
Arithmetic \\
Average
\end{tabular} & $\begin{array}{l}\text { Standard } \\
\text { deviation } \\
\end{array}$ & $\begin{array}{c}\text { Degrees of } \\
\text { freedom } \\
\end{array}$ & \begin{tabular}{|c|}
$\begin{array}{c}\text { Value } \\
(t)\end{array}$ \\
\end{tabular} & $\begin{array}{c}\text { Level of } \\
\text { significance } \\
\end{array}$ \\
\hline Family & $\begin{array}{c}\text { Sciences } \\
\text { Humanities } \\
\end{array}$ & $\begin{array}{l}381 \\
493 \\
\end{array}$ & $\begin{array}{c}20.546 \\
21.014 \\
\end{array}$ & $\begin{array}{l}2.857 \\
2.915 \\
\end{array}$ & 872 & 2.282 & $\begin{array}{c}0.023 \\
\text { Function } \\
\end{array}$ \\
\hline School & $\begin{array}{c}\text { Sciences } \\
\text { Humanities }\end{array}$ & $\begin{array}{l}381 \\
493 \\
\end{array}$ & $\begin{array}{l}21.047 \\
21.318 \\
\end{array}$ & $\begin{array}{l}4.755 \\
4.105 \\
\end{array}$ & 872 & 0.904 & $\begin{array}{c}0.366 \\
\text { Non-function }\end{array}$ \\
\hline Community. & $\begin{array}{c}\text { Sciences } \\
\text { Humanities } \\
\end{array}$ & $\begin{array}{l}381 \\
493 \\
\end{array}$ & $\begin{array}{l}20.732 \\
21.663 \\
\end{array}$ & $\begin{array}{l}3.339 \\
3.275 \\
\end{array}$ & 872 & 4.131 & $\begin{array}{c}\text { o.ooo } \\
\text { Function } \\
\end{array}$ \\
\hline $\begin{array}{l}\text { The total degree } \\
\text { of social factors }\end{array}$ & $\begin{array}{c}\text { Sciences } \\
\text { Humanities } \\
\end{array}$ & $\begin{array}{l}381 \\
493 \\
\end{array}$ & $\begin{array}{l}62.343 \\
63.995 \\
\end{array}$ & $\begin{array}{l}8.138 \\
7.514 \\
\end{array}$ & 872 & 3.108 & $\begin{array}{c}0.002 \\
\text { Function } \\
\end{array}$ \\
\hline
\end{tabular}

Table 6 explains that there are differences that are statistically functional at o.or between grades averages of science and humanity students in social dimension of the total score of scale of social factors. On one hand, differences between average grades of science and humanity students in the family dimension are statistically functional at 0.05 in favor of students specializing in humanities. On the other hand, Table 6 explains that there are no statistically functional differences between average grades of science and humanity students in the school dimension. Based on these results, the authors reject zero imposition and accept the alternative hypothesis, which states that there are statistically significant differences between the average grades of students of sciences and humanities on the scale of social factors in favor of humanities.

The results of the second hypothesis explain that there are statistically significant differences at the level 0.01 between the averages of grades of sciences and humanities students in the community dimension and the overall degree of the scale of social factors, and at the level of 0.05 in the family dimension, all in favor of students od humanities. However, there are no statistically significant differences between sciences and humanities students regarding the school dimension, and the authors 
think that that could be due to the fact that there are no differences in the study environment between sciences and humanities at King Faisal University because all students have access to same services.

\subsection{Results of verification of the third hypothesis}

This hypothesis states that there are no statistically significant differences between grade averages scoring of students of sciences and students of humanities on the scale of compliance with traffic rules. To verify the validity of this hypothesis, the authors used the (t-test) for the independent groups to look for statistically functional differences in grade averages of students of sciences and of humanities on the scale of compliance with traffic rules as Table 7 explains.

Table 7: The differences between the average grades of students of sciences and humanities on the scale of compliance with traffic rules

\begin{tabular}{|c|c|c|c|c|c|c|c|}
\hline Dimension & Specialization & Number & $\begin{array}{c}\text { Average } \\
\text { arithmetic }\end{array}$ & $\begin{array}{l}\text { Standard } \\
\text { deviation }\end{array}$ & $\begin{array}{l}\text { Degrees of } \\
\text { freedom }\end{array}$ & \begin{tabular}{|c|} 
Value \\
$(\mathrm{t})$
\end{tabular} & \begin{tabular}{|c|}
$\begin{array}{c}\text { Level of } \\
\text { significance }\end{array}$ \\
\end{tabular} \\
\hline $\begin{array}{l}\text { Total degree of traffic } \\
\text { commitment }\end{array}$ & $\begin{array}{c}\text { Sciences } \\
\text { Humanities } \\
\end{array}$ & $\begin{array}{l}381 \\
493 \\
\end{array}$ & $\begin{array}{l}58.766 \\
56.803 \\
\end{array}$ & $\begin{array}{l}5.857 \\
5.799 \\
\end{array}$ & 872 & 4.941 & $\begin{array}{c}0.000 \\
\text { function }\end{array}$ \\
\hline
\end{tabular}

Table 7 explains that there are statistically significant differences at the level of o.or between the averages of students of sciences and humanities on the overall score of compliance with traffic rules in favor of science students, and therefore the authors reject zero imposition and accept the alternative hypothesis, which states that there are statistically significant differences between the average scores of students of sciences and humanities on the scale of compliance with traffic rules in favor of science students.

Regarding the results of the third hypothesis, there are statistically significant differences between the averages of grades of sciences and humanities students in compliance with traffic rules in favor of sciences students, which the authors thing that it could be because of sciences disciplines may have influenced sciences students to comply with traffic rules and therefore they calculate losses that the non-compliance with traffic rules might cause, even though the differences between the students of sciences and the students of humanities regarding the community factors work in favor of the students of humanities, the students of humanities could not benefit from them in the compliance with traffic rules and standards.

\section{Discussion of Results}

The results of the study reveal that familial, educational and communal factors contribute significantly to the prediction of university student motorists' compliance with traffic rules. The results of the first hypothesis explain the existence of three statistically functioning models for the prediction of sample members' compliance with traffic rules as the following models explain.

Model 1: Tables 4 and 5 illustrate that the regression of coefficients for family factors in the regression equation are statistically significant at 0.01 , indicating that family factors make a statistically significant contribution to the prediction of compliance with traffic rules among study sample members, and, therefore, the compliance with traffic rules of university students who drive can be predicted through the following multiple gradient equation (the prediction equation).

Compliance with traffic rules $=51.094+(0.315 \times$ score of family factors $)$.

This indicates that family factors are the highest contributing factors, and act as a single and effective independent variable in predicting compliance with traffic rules in the sample population and consequently among university student motorists, which demonstrates the strength and importance of family factors in compliance with traffic rules among students.

Model 2: The tables (Table 4 and Table 5) further illustrate that the regression coefficients for 
family and school factors in the regression equation are statistically significant at o.o1, which indicates that both family and school factors contribute significantly to the prediction of compliance with traffic rules among the sample members, and, consequently, contribute to the students' compliance with traffic rules that can be predicted by applying the following multiple regression equation (equation prediction) : factors).

Compliance with traffic rules $=44.693+(0.255 \times$ family factors score $)+(0.361 \times$ score of study

This illustrates the importance of family and school factors in adhering to traffic rules among the sample members and therefore among university youth motorists.

Model 3: The same tables again show that the regression coefficients for family and communitybased factors in the regression equation are statistically significant at o.o1, except for the family factors in this model, where they are statistically functional at 0.05, which shows that family, school and community factors jointly contribute significantly to the prediction of compliance with traffic rules among the sample members, and therefore the university students' compliance with traffic rules can be predicted as the following multiple gradient regression equation explains:

Compliance with traffic rules $=42.931+(0.154 \times$ family factors score $)+(0.288 \times$ score of studying factors $)+(0.254 \times$ score of community factors $)$.

This demonstrates the importance of both family, school and community factors in the sample members' adherence to traffic rules and the adherence of university students who drive in general.

These findings of the study are explained in light of the important role that family, school and community factors play in the prediction of the compliance of university students who drive with traffic rules. It is obvious that family factors have had the greatest impact on the university students' observation of traffic rules, followed by school factors and then community factors. The prominence of family factors regarding the young motorists' compliance with traffic rules is due to the key role that parents and other older relatives play in the inculcation of ethical and social standards and rules to children, including the observation of traffic rules as part of their duty during the process of children upbringing, which happens in both direct and indirect avenues. By indirect avenues is meant that when older people-- especially relatives, behave gently in front of younger ones, they become the role models for them and therefore it is important that older people carefully watch their own behaviors and act according to the prevalent rules and laws so that the younger people can follow their lead in all key areas, including the observation of driving rules.

The school factors scored the second highest level of influence on the compliance of university students with traffic rules and driving standards, because there are faculty members and other authorities who advise students on the importance of adherence to traffic rules. There are also university courses that include aspects of driving problems and traffic rules in their contents, in addition to workshops that are organized from time to time on traffic safety issues. These classes, workshops and orientations enlighten students on traffic rules, including the respect for traffic lights rules, speed limits, and traffic signs in general. The university also urges students to attend the Gulf Traffic Week that is organized every year which educates people about traffic rules and consequences of reckless driving which include deaths, injuries, disabilities and financial losses.

Finally, community factors rank third in the influence of students' commitment to traffic standards and safety rules, which means that community also plays a crucial role in the education of students on safe driving and avoidance of accidents. The community educates drivers through media, makes available driving schools and training centers to the public, provides traffic management institutions, builds roads, and puts lights and road signs. It plays a crucial role even though it trailed both the family and school in influencing students to comply with traffic rules and follow safety standards. This is because families, schools and university are specific institutions whose mission is to train individuals since when they are very young on various aspects of life before they are released to assume their roles as community members after they grow up and are ready to act responsibly. Families and schools shape people culturally and polish their attitudes with values and ethics that reflect on their personalities and behaviors in their communities as well as other societies to where they travel or in which they live. 
These results confirm results of previously conducted studies (Trueloves, Freeman \& Davey, 2019; Holman\& Popusoi 2018; Xu, Li \& Jiang, 2014; Mawanga and Ntayi, 2010), which revealed that social factors have a pivotal role in derivers' compliance with traffic rules and safety standards or their violation, and emphasized the importance of compliance with traffic rules and safety standards to be an essential part of the urban culture in order to reduce traffic accidents (Mawanga \& Jntayi, 2010). Therefore, the present study emphasizes that family, school and community together can significantly contribute to the reduction of traffic accidents and will save millions of lives and billions of dollars every year if enlightenment on traffic accidents becomes a key part of daily activities as earlier studies also demonstrated (Lee \& Al-Mansour, 2019; Penmetsa, \& Pulugurtha, 2017; Yusuf, 2017).

\section{Conclusions and Recommendations}

The study concludes that social factors play an important and effective role in the prediction of university students' compliance with traffic rules as its results have shown in the three models of the prediction of compliance with traffic rules. The first model of the prediction of compliance with traffic rules explains the importance of the family factors role, whereas the second model refers to the contribution of both family and school factors to the prediction of compliance of university students who drive with traffic rules. The contribution of both family and school factors is statistically significant to students' commitment to traffic rules, which emphasizes the importance of their respective roles. The third model indicates the contribution of family, school and community factors together to the prediction of students' compliance with traffic rules. The contribution of family, school and community together is statistically significant regarding the commitment of the university students to traffic rules and driving standards. Together, they constitute social factors that help students adhere to traffic rules, because they instill values and principles of traffic rules and driving standards in university students and enhance their compliance with traffic rules, which consequently contributes positively to the reduction of accident rates and casualties resulting from them.

The results of the study urged authors to make the following recommendations:

1. It is important that families intensify the role of instilling in their children the principles and values that enhance compliance with traffic rules and driving standards.

2. It is recommended that educational institutions play more role towards educating and training students on traffic rules, through lectures, workshops, training courses, seminars, conferences and scientific research.

3. Universities should adopt traffic points programs to encourage students to comply with driving rules and safety standards.

4. Community institutions should intensify the education of people through the media about the importance of observation of driving rules and safety standards since that would reduce traffic accidents significantly.

5. The application of points system for traffic violations would also help significantly with the reduction of traffic accidents, because it would serve as a force compelling drivers to be more cautious while driving.

6. Traffic authorities should increase road surveillance cameras to hold traffic violators accountable.

In light of the results of the study, the authors suggest the following areas for future research activities regarding the traffic in Saudi Arabia and other parts of the world:

1. Research projects for educating youth in general and university youth in particular about the importance of compliance with traffic rules.

2. Research activities addressing the relationship between abiding by traffic rules and a personal success socially and economically.

3. Research activities focusing on the family role in the reduction of traffic accidents, because family provides the primary socialization, which has the strongest effect on people compared to other areas of socialization. 


\section{Rerences}

Abdul Majid, M., Al-Daghheri, M.\& Faraj, M., (2014). A Proposed Vision of the Role of Educational Institutions in Qassim Region in Developing Youth Awareness of Traffic Hazards. Journal of Educational and Psychological Sciences, Qassim University, 7(2), 517-583.

Al-Radadi, S., (2013). Methods of Development of Traffic Culture and its Educational Applications, (unpublished Master's thesis). Medina: Faculty of Da'wa and The Origins of Religion, Islamic University of Medina.

Castillo-Manzano, J., Castro-Nuno, M., Lopez-Valpuesta, L. \& Pedregal, D., (2019). From Legislation to Compliance: The Power of Traffic Law Enforcement for the Case Study of Spain. Transport Policy, (75), 1-9.

Fadhil, R. (2013). The Phenomenon of Road Traffic Accidents Causes, Effects and Ways to Reduce them: The Case Study of Algeria. Journal of Economics, Management and Trade Sciences, (270, 351-376.

Garrido, J., Rodríguez, G., Fernández, M., Castro, Y., Fernández, M., \& Soriano, L., (2018). A Qualitative Approach to the Study of the Characteristics of Individuals Convicted of Road Traffic Offences. International Journal of Law and Psychiatry, (59), 10-19.

Hamad, H., (2008). The Impact of Social Factors in Juvenile Delinquency: A Field Study on the Governorate of Gaza. Al-Azhar University Magazine, 10(2), 93-150.

Holman, A. \& Popusoi, S., (2018). Ethical Predispositions to Violate or Obey Traffic Rules and the Mediating Role of Driving Styles. The Journal of Psychology, 152(5), 257-275.

Ladi, B., (2016). Traffic Education and Ways to Prevent Traffic Accidents in Algeria. Journal of Social Studies, (20), 74-84.

Ladi, B., (2014). The Impact of Human Behaviour on Traffic Accidents in Algeria. Al-Hikma Journal of Social Studies, (28), 82-95.

Lee, M. \& Al-Mansour, A., (2019). Development of a New Traffic Safety Education Material for the Future Drivers in the Kingdom of Saudi Arabia. Journal of King Saud University - Engineering Sciences, 3(3), 201-208.

Ludovic, G., Ordonneau, P., Plot, E., Toillon, C., Ingrand, P.\& Romo, L. (2017). Description of Various Factors Contributing to Traffic Accidents in Youth and Measures Proposed to Alleviate Recurrence. Frontiers in Psychiatry, 8(94), 1-10.

Mawanga, F, \& Ntayi, J., (2010). Social Norms and Compliance with Road Traffic Rules in Urban Areas: Initial Impressions of Drivers in Kampala, Uganda. Journal of Transport and Supply Chain Management, November 2010, 138-150.

Najmi, A., (2017). Field Study of the Educational Role of Tabuk University in Achieving Traffic Safety from the Point of View of Faculty Members. Journal of Scientific Research in Education, Ain Shams University, 2 (18),117-143.

Penmetsa, P. \& Pulugurtha, S. (2017). Risk Drivers Pose to Themselves and Other Drivers by Violating Traffic Rules. Traffic Injury Prevention, 18(1), 63-69.

Trueloves, V., Freeman, J., \& Davey, J., (2019). You Can't Be Deterred by Stuff You Don't Know About": Identifying Factors that Influence Graduated Driver Licensing Rule Compliance. Safety Science, (111), 313-323.

Weichbrodt, J., (2015). Safety Rules as Instruments for Organizational Control, Coordination and Knowledge: Implications for Rules Management. Safety Science, (80): 221-232.

World Health Organization, 2015. Global Status Report on Road Safety.

Yusuf, M., (2017). Use of Analytical Analysis to Identify the Most Important Factors Affecting the Occurrence of Traffic Accidents in Khartoum State During 2016 (unpublished Master's Thesis). Khartoum: Graduate School, University of Khartoum.

Xu, Y., Li, Y. \& Jiang, L., (2014). The Effects of Situational Factors and Impulsiveness on Drivers' Intentions to Violate Traffic Rules: Difference of Driving Experience. Accident Analysis and Prevention, (62), 54- 62.

Zhang, Q., Ge, Y., Qu, W., Zhang, K. \& Sun, X. (2018). The traffic climate in China: The Mediating Effect of Traffic Safety Climate Between Personality and Dangerous Driving Behavior. Accident Analysis and Prevention, (113): $213-223$.

Zhang, G., Tan, Y. \& Jou, R., (2016). Factors Influencing Traffic Signal Violations by Car Drivers, Cyclists, and Pedestrians: A Case Study from Guangdong, China. Transportation Research, Part F (42), 205-216. 